\title{
ГИГИЕНИЧЕСКАЯ ОЦЕНКА УСЛОВИЙ ПРОФЕССИОНАЛЬНОГО ОБУЧЕНИЯ ПОДРОСТКОВ С ОГРАНИЧЕННЫМИ ВОЗМОЖНОСТЯМИ: ПРОБЛЕМЫ И ПУТИ ОПТИМИЗАЦИИ
}

\author{
Ю. В. Елисеева ${ }^{1 凶}$, А. А. Войтович1, О. Ю. Милушкина², А. В. Истомин ${ }^{3}$ Ю. Ю. Елисеев ${ }^{1}$
}

${ }^{1}$ Кафредра общей гигиены и экологии, Саратовский государственный медицинский университет имени В. И. Разумовского, Саратов

${ }^{2}$ Кафедра гигиены, Российский национальный исследовательский медицинский университет имени Н. И. Пирогова, Москва

${ }^{3}$ Отдел здорового и безопасного питания, Институт комплексных проблем гигиены, Федеральный научный центр гигиены имени Ф. Ф. Эрисмана, Москва

\begin{abstract}
Для восполнения недостатка трудовых кадров по ряду профессий представляется возможным использование экономически активной части населения страны, в том числе лиц с ограниченными возможностями (ОВ). К сожалению, соблюдение гигиенических требований в ходе профессионального обучения подростков с ОВ недостаточно изучено, поскольку в основном имеются данные об исследованиях условий подготовки только здоровых подростков. Целью работы были изучение условий профессионального обучения подростков с ОВ, разработка мероприятий по улучшению условий их труда с учетом имеющейся патологии. Подростки с ОВ (120 человек) в возрасте 16-18 лет с сохраненным интеллектом, обучающиеся в интернате по специальностям оператор швейного оборудования, обувщик по ремонту обуви, обследованы по показателям адаптационного потенциала, тревожности, умственной работоспособности, а также заболеваемости и субъективной оценке самочувствия. Использовали гигиенические критерии Смирнова, анкетирование с помощью Гиссенского опросника, тест Спилбергера, шкалу Сивкова, корректурные таблицы, методику Баевского. Для статистического анализа применены параметрический ( $t$-критерий Стьюдента) и непараметрический (Манна-Уитни) критерии. Связь изучаемых параметров определена по коэффициенту корреляции Спирмена. Выявлены ведущие неблагоприятные гигиенические факторы, оказывающие значимое влияние на организм учащихся: тяжесть и напряженность трудового процесса, недостаточный уровень искусственной освещенности, превышение уровня шума, высокое содержание органических растворителей и уровня пыли в воздухе рабочей зоны. Определено нерационально составленное расписание учебных занятий в интернате. Результаты исследования позволили разработать и внедрить компьютерную программу автоматизированного составления расписания, позволяющую улучшить психосоматическое состояние здоровья и вдвое снизить количество жалоб на самочувствие.
\end{abstract}

Ключевые слова: учащиеся с ограниченными возможностями, профессиональное обучение, факторы учебнопроизводственной среды, адаптация, расписание занятий

$\varangle$ Для корреспонденции: Юлия Викторовна Елисеева ул. Б. Казачья, д. 112, г. Саратов, 410012; eliseeva-gig@mail.ru

Статья получена: 17.06.2018 Статья принята к печати: 16.11 .2018

DOI: $10.24075 /$ vrgmu.2018.060

\section{HYGIENIC ASSESSMENT OF HANDICAPPED ADOLESCENTS VOCATIONAL TRAINING CONDITIONS: PROBLEMS AND OPTIMIZATION OPPORTUNITIES}

\author{
Eliseeva YuV ${ }^{1 凶}$, Voytovich $\mathrm{AA}^{1}$, Milushkina OYu², Istomin AV , Eliseev YuYu ${ }^{1}$ \\ General Hygiene and Ecology Department, Razumovsky Saratov State Medical University, Saratov \\ ${ }^{2}$ Hygiene Department, Pirogov Russian National Research Medical University, Moscow \\ ${ }^{3}$ Healthy and Safe Nutrition Department, Institute for Complex Hygiene Problems, Erisman Federal Research Center for Hygiene, Moscow
}

In a number of occupations, there is a shortage of labor force that can be filled with economically active part of the population, including people with disabilities (handicapped, HC). Unfortunately, observance of hygienic requirements in the context of HP adolescents vocational training has not been studied sufficiently: most scholars have researched only the conditions of teaching healthy adolescents. This study aimed to examine the HC adolescents vocational training conditions and develop measures to improve their working conditions with pathologies factored in. We examined adaptation potential, anxiety level, mental efficiency, sick rate and personal well-being assessment in HC adolescents $(n=120)$ aged $16-18$, not impaired intellectually, studying sewing equipment operation, shoe repairs in the boarding scool. In the context of the study, we applied Smirnov hygiene criteria, Giessen Symptom Questionnaire, Spielberger's Test Anxiety Questionnaire, Sivkov scale, correction tables, Baevsky adaptation index. For the purposes of statistical analysis, we used parametric (Student $t$-test) and nonparametric (Mann-Whitney) criteria. The Spearman's correlation coefficient helped determine interrelationship of the studied parameters. We identified the following key adverse hygienic factors that have a significant impact on the students' health: intense character of labor performed, insufficient artificial lighting, noise level above the norm, high content of organic solvents and dust in the workshop's air. The timetable of the boarding school was also found to be inefficient. The results of this study allowed developing and introducing a software program to automatically compile the school's timetable with the aim to improve psychosomatic health of the students and halve the number of health-related complaints.

Keywords: handicapped students, vocational training, training and production environment factors, adaptation, classes timetable

$\triangle$ Correspondence should be addressed: Yulia V. Eliseeva

B. Kazachya 112, Saratov, 410012; eliseeva-gig@mail.ru

Received: 17.06.2018 Accepted: 16.11.2018

DOI: $10.24075 /$ brsmu.2018.060 
Проблема сохранения и укрепления здоровья подростков актуальна на современном этапе и является важнейшей государственной задачей [1, 2]. Негативные сдвиги в состоянии здоровья детей и подростков привели к увеличению инвалидности, что ограничивает получение ими профессионального образования по состоянию здоровья [3-6]. Принятый в 1995 г. закон «О социальной защите инвалидов в Российской Федерации» гарантирует социальную защиту людям с инвалидностью, а также возможность свободного получения образования. Однако реализация профессиональной подготовки подростков с ограниченными возможностями (ОВ) существенно ограничена. Более того, на состояние здоровья подростков, получающих профессиональное образование различного профиля, оказывают влияние факторы учебно-производственной среды [7-10]. Наиболее ранними критериями оценки изменений в состоянии здоровья подростков, возникающими в процессе профессионального обучения, являются нарушения адаптационных механизмов, сопровождаемые морфофункциональными расстройствами в организме учащихся [11, 12]. Для повышения эффективности профессионального обучения необходимо знать, как лица с ОВ приспосабливаются к условиям обучения. В связи с этим практический интерес представляет изучение вопросов адаптации подростков-инвалидов к условиям обучения в учреждениях среднего профессионального образования.

Целью исследования были изучение условий профессионального обучения подростков с ОВ и разработка мероприятий по адаптации учащихся $\mathrm{k}$ факторам учебно-производственной среды.

\section{ПАЦИЕНТЫ И МЕТОДЫ}

Исследование проводили на базе ГАПОУ «Саратовский комплекс-интернат профессионального обучения для инвалидов и лиц с ограниченными возможностями здоровья» в период 2016-2017 гг. (утверждено комитетом по этике Саратовского ГМУ им. В. И. Разумовского, протокол №3 от 7 ноября 2017 г.). В соответствии с Федеральным законом «Об основах охраны здоровья граждан в Российской Федерации» от 21 ноября 2011 г. № 323-ФЗ (ред. от 3 июля 2016 г.), все обследуемые давали информированное добровольное согласие на выполнение исследований, а в соответствии с требованиями ст. 9 Федерального закона «О персональных данных» от 27 июля 2006 г. № 152-Ф3 - на обработку персональных данных.

Объектом изучения были факторы учебнопроизводственной среды, оказывающие влияние на процессы адаптации учащихся. В исследуемую группу вошли 120 подростков с ОВ в возрасте 16-18 лет, из которых 58\% имели инвалидность I-III степени. Критерии включения учащихся в исследование: обучение в интернате по специальностям оператор швейного оборудования, обувщик по ремонту обуви; сохранность интеллекта. Критерии исключения: выраженность психических расстройств; низкий интеллектуальный уровень; конфликтность.

Изучение организации учебно-профессиональной подготовки осуществляли на основе хронометражных исследований (записи по секундомеру времени и последовательности выполнения отдельных видов работ (ручных операций). Рациональность организации теоретических и практических занятий оценивали на основании гигиенических критериев, предложенных Н. К. Смирновым [13], правильность распределения ежедневной и еженедельной нагрузки определяли путем расчета коэфффициента ежедневной учебной нагрузки [14]. Объективные данные о состоянии здоровья учащихся получены из формы 086/y, утвержденной Минздравом РФ 8 декабря 2014 г. Изучение структуры и причин инвалидности проводилось на основании анализа формы индивидуальной программы реабилитации инвалида (утв. Приказом Минздравсоцразвития России от 4 августа 2008 г. № 379н). Оценивали уровень и структуру заболеваемости по классам и нозологическим формам в соответствии с МКБ-10.

Субъективная оценка состояния здоровья выполнена по данным анкетирования учащихся (Гиссенский опросник психосоматических жалоб) [15].

Оценка уровней личностной и ситуативной тревожности подростков проводилась по тесту Ч. Д. Спилбергера [16].

Значения адаптационных показателей (АП) в оценке уровня адаптационных возможностей организма рассчитывали по методике Р. М. Баевского в модификации А. П. Берсеневой (1995) [17].

Умственную работоспособность (УР) изучали по данным корректурных таблиц В. Я. Анфимова в модификации С. М. Громбаха [18].

Достоверность различий изучаемых параметров анализировали с применением нескольких критериев: $t$-критерия Стьюдента, Манна-Уитни, достоверности различий между средними показателями (р). Для всех проведенных исследований различия считали достоверными при двустороннем уровне значимости $p<0,05 ; p<0,01 ; p<0,001$, минимальная достоверность различий составила 95\%. Для определения тесноты и достоверности связи между параметрами применяли критерий ранговой корреляции Спирмена (r). Полученные данные обрабатывали с помощью IBM PC, использовали табличный процессор MS Excel и статистический пакет Statistica 6.0.

\section{РЕЗУЛЬТАТЫ ИССЛЕДОВАНИЯ}

\section{Оценка условий обучения при освоении профессии обувщика}

При оценке условий обучения подростков с ОВ в процессе освоения профессии обувщик по ремонту обуви следует отметить наличие фактора тяжести трудового процесса (работа выполнялась в вынужденной рабочей позе, в положении сидя более 80\% времени практического занятия). Уровни искусственной освещенности на рабочих местах были недостаточными (освещенность в учебных мастерских на рабочей поверхности верстаков составляла 226,5 \pm 13,8 лк; норма - 300 лк). В воздухе рабочей зоны учащихся определялись вещества в концентрациях, превышающих предельно допустимые (ацетон - до 4,5 предельно допустимых концентраций (ПДК), диоксид углерода - до 1,5 ПДК). Среднесменные концентрации умеренно опасных промышленных аллергенов (канифоль, формальдегид) не превышали предельно допустимых значений. С учетом выявленных концентраций химических веществ в воздухе рабочей зоны условия труда подростков с ОВ следует признать вредными. Более того, оценка образовательного процесса показала, что профессиональное занятие при освоении профессии обувщик по ремонту обуви также нельзя 
считать рациональным по продолжительности различных видов деятельности и частоте их чередования.

\section{Оценка условий обучения при освоении профессии оператора швейного оборудования}

Гигиеническая оценка условий профессионального обучения подростков при освоении профессии оператор швейного оборудования показала, что на учащихся воздействует ряд факторов: 1) фактор тяжести трудового процесса (рабочие операции выполнялись в вынужденной позе в положении сидя с наклоном туловища вперед и занимали 82\% времени занятия); 2) фактор напряженности, связанный с длительным сосредоточением внимания за одним объектом, занимавшим более 40\% времени занятия; 3) фактор освещенности (уровни искусственной освещенности при выполнении машинных работ достигали лишь 1456,2 \pm 24,1 лк при норме 2000 лк, $p=0,15$; на утюжильных рабочих местах и столах для выполнения ручных работ - 350,7 \pm 13,7 лк при норме 600 лк, $p=0,03$ ); 4) «шумовой» фактор (при выполнении ручных и утюжильных рабочих операций в мастерской уровень звукового давления составлял 82,4 \pm 2,4 дБ; превышения уровней звукового давления на 9,5 \pm 3,2 дБ регистрировались в диапазоне частот от 500 до 8000 Гц; суммарное время действия шума составляло 54,3\% времени занятия; эквивалентный уровень шума достигал 82,4 \pm 2,4 дБ, что превышало допустимые значения на 2 дБ). Полученные результаты связывали с неправильной организацией рабочих мест в мастерской: рабочие места для выполнения ручных, утюжильных и машинных рабочих операций были расположены в непосредственной близости друг от друга в одном помещении. При выполнении работ на швейной машине уровень звука составлял 87,1 2 2,1дБ, на машине цепного переплетения нитей $-85,2 \pm 3,5$ дБ, что превышало предельно допустимые уровни (ПДУ), равные 80 дБ.

\section{Оценка заболеваемости учащихся}

Общая заболеваемость учащихся, по данным обращаемости в первом полугодии обучения, составила 5,23 случая на 1000 человек. Во втором полугодии значения данного показателя достоверно превышали $(p<0,01)$ показатели первого полугодия и составили 7,08 случаев на 1000 учащихся. Значение показателя патологической пораженности в коллективе составляло 199,5 \pm 16,7 на 100 человек. В структуре патологической пораженности преобладали отклонения нервно-психической сферы (43,8\%), нарушения опорно-двигательного аппарата (18,3\%), нарушения системы кровообращения (16,5\%).

\section{Оценка работоспособности учащихся}

Умственную работоспособность (УР) учащихся оценивали в начале и по окончании занятия по каждой из изучаемых дисциплин (табл. 1). Интегральная оценка УР показала, что в начале занятий большинство подростков $(64,2 \pm 3,1 \%)$ имели низкий ее уровень и только часть $(14,2 \pm 2,1 \%)$ высокий. По окончании занятий акценты распределения уровней УР смещались в сторону увеличения количества учащихся с высоким уровнем $(35,4 \pm 3,3 \%)$ и сокращением числа подростков с низким уровнем работоспособности (до 25,8 \pm 0,9\%). Выявленная динамика обусловлена длительным периодом врабатываемости, что является особенностью функционирования ЦНС подростков с ОВ.

Распределение уровней УР учащихся С ОВ в течение недели оценивали по способу, предложенному П. В. Нефедовым, Н. Б. Кутумовой [14]. В основе распределения уровней работоспособности лежали значения коэффициента ежедневной учебной нагрузки (табл. 2). Недельная динамика работоспособности характеризовалась низкими значениями показателей в понедельник, что могло быть связано с изменением режима дня (отьезд в субботу большинства учащихся домой и возвращение в понедельник утром). Резкий подъем работоспособности без нарастания отмечен во вторник и среду с последующим постепенным снижением от четверга к субботе, что свидетельствует о преобладании в ЦНС процессов торможения вследствие развития утомления.

Более детальный анализ динамики уровней работоспособности подростков с ОВ в течение учебного дня позволил выявить некоторые отличия от классической кривой дневной работоспособности. Наиболее высокие уровни работоспособности подростков регистрировались на 3-4-й ч работы. Далее следовал период снижения работоспособности и стадия конечного порыва, характеризующаяся кратковременным подъемом работоспособности, смещенным на 2-3 ч в сравнении с классическим распределением.

\section{Оценка адаптационных возможностей}

Оценка адаптационных возможностей организма подростков позволила установить, что $39,3 \pm 1,1 \%$ юношей имели значения адаптационного показателя (АП) от 8,25 до 9,86 (соответствуют неудовлетворительному уровню адаптации). Среди девушек 34,5 \pm 1,6\% имели неудовлетворительный уровень адаптации и 26,5 \pm 0,7\% характеризовались напряжением механизмов адаптации.

Число учащихся с удовлетворительным уровнем адаптации среди юношей на 26,3\% меньше, чем среди девушек. Увеличение значений АП может рассматриваться как неблагоприятная тенденция к ухудшению состояния здоровья, связанная со снижением работоспособности и развитием утомления.

Выявлено, что неудовлетворительную адаптацию имели 48,1\% среди подростков, не имеющих инвалидности, и 41,6\% среди имеющих инвалидность.

Результат оценки средних значений тревожности показал низкий уровень ситуативной и умеренный уровень личностной тревожности уподростков. Среди обследуемых с ОВ низкая ситуативная тревожность (< 30 баллов) была выявлена у 76,2\%, что свидетельствовало о депрессивном, ареактивном состоянии с низким уровнем мотивации $\mathrm{k}$ обучению. Умеренная ситуативная тревожность (33-44 балла) определялась у 23,8\% учащихся. Выявленное значительное количество подростков $(51,3 \%)$ с высоким значением показателей личностной тревожности среди учащихся, осваивающих профессию оператор швейного оборудования (52 \pm 1,4 балла), связано со склонностью воспринимать широкий спектр жизненных ситуаций как угрожающие и отвечать на них выраженной реакцией. Данная тенденция отражала особенности склада личности учащихся в этой группе.

Результаты корреляционного анализа позволили установить, что в качестве условий успешной адаптации подростков с ОВ к микросреде профессионального 
образовательного учреждения можно выделить проживание в общежитии ( $r=0,32)$. Кроме того, выявлена прямая умеренная связь АП с уровнем личностной тревожности $(r=0,36)$. Уровень личностной тревожности характеризует особенности склада личности и функционирование организма в условиях стресса. Таким образом, подростки с низким уровнем стресса лучше адаптировались к условиям профессионального обучения в учреждении. В отношении уровня ситуативной тревожности и показателя адаптации установлена умеренная обратная связь $(r=-0,38)$. Учащиеся с низкой мотивацией к обучению имели неудовлетворительные показатели адаптации.

\section{Оценка учебного расписания}

Центральной проблемой обучения и воспитания подростков с ОВ при переходе к профессиональному образованию является увеличение учебно-производственной нагрузки за счет специальных предметов (технология, материаловедение, профессиональное обучение и другие), что затрудняет составление расписания.

Одним из возможных способов гигиенической оценки расписания считается использование ранговой шкалы трудности предметов, предложенной И. Г. Сивковым [18]. Однако ее невозможно использовать для оценки учебного расписания в учреждении профессионального образования ввиду отсутствия в шкале специальных образовательных предметов.

Оценку уровня трудности изучаемых предметов проводили по функциональному состоянию ЦНС (изучали показатели УР, использовали корректурные таблицы). Анализ показателей функционального состояния ЦНС в динамике позволил обнаружить определенные тенденции В изменении изучаемых показателей у учащихся с ОВ (табл. 3).

Таким образом, учебным предметам присваивали следующее количество баллов (табл. 4). Данную шкалу утомительности сравнили с существующей ориентировочной шкалой трудности учебных дисциплин

Таблица 1. Результаты изучения умственной работоспособности подростков с ОВ по данным корректурных таблиц В. Я. Анфимова в модификации С. М. Громбаха

\begin{tabular}{|c|c|c|c|c|c|c|c|c|c|c|c|c|}
\hline \multirow{2}{*}{$\begin{array}{c}\text { Изучаемые } \\
\text { предметы }\end{array}$} & \multicolumn{2}{|c|}{$\begin{array}{c}\text { Количество } \\
\text { просмотренных } \\
\text { букв }\end{array}$} & \multirow{2}{*}{$\begin{array}{l}t \text {-Критерий } \\
\text { Стьюдента }\end{array}$} & \multirow{2}{*}{$p$} & \multicolumn{2}{|c|}{$\begin{array}{c}\text { Среднее количе- } \\
\text { ство ошибок на } \\
500 \text { знаков }\end{array}$} & \multirow{2}{*}{$\begin{array}{l}t \text {-Критерий } \\
\text { Стьюдента }\end{array}$} & \multirow{2}{*}{$p$} & \multicolumn{2}{|c|}{$\begin{array}{c}\text { Точность } \\
\text { выполнения } \\
\text { задания (\%) }\end{array}$} & \multicolumn{2}{|c|}{ Продуктивность } \\
\hline & $\begin{array}{l}\text { Начало } \\
\text { занятия }\end{array}$ & $\begin{array}{c}\text { Конец } \\
\text { занятия }\end{array}$ & & & $\begin{array}{l}\text { Начало } \\
\text { занятия }\end{array}$ & $\begin{array}{c}\text { Конец } \\
\text { занятия }\end{array}$ & & & $\begin{array}{l}\text { Начало } \\
\text { занятия }\end{array}$ & $\begin{array}{c}\text { Конец } \\
\text { занятия }\end{array}$ & $\begin{array}{l}\text { Начало } \\
\text { занятия }\end{array}$ & $\begin{array}{c}\text { Конец } \\
\text { занятия }\end{array}$ \\
\hline $\begin{array}{l}\text { Профессиональное } \\
\text { занятие }\end{array}$ & $\begin{array}{c}445,2 \pm \\
9,1\end{array}$ & $\begin{array}{c}479,3 \pm \\
11,4\end{array}$ & 2,39 & 0,004 & $\begin{array}{c}53,9 \pm \\
2,7\end{array}$ & $\begin{array}{c}49,9 \pm \\
1,8\end{array}$ & 1,23 & 0,0001 & $\begin{array}{c}89,1 \pm \\
3,2\end{array}$ & $\begin{array}{c}90,7 \pm \\
2,4\end{array}$ & $\begin{array}{c}4,9 \pm \\
0,2\end{array}$ & $\begin{array}{c}5,2 \pm \\
0,5\end{array}$ \\
\hline $\begin{array}{l}\text { Технология } \\
\text { производства }\end{array}$ & $\begin{array}{c}580,4 \pm \\
10,5\end{array}$ & $\begin{array}{c}452,1 \pm \\
8,7\end{array}$ & 10 & 0,019 & $\begin{array}{c}50,9 \pm \\
1,3\end{array}$ & $\begin{array}{c}73,0 \pm \\
4,1\end{array}$ & 5,14 & 0,001 & $\begin{array}{c}91,9 \pm \\
1,5\end{array}$ & $\begin{array}{c}86,0 \pm \\
1,9\end{array}$ & $\begin{array}{c}6,3 \pm \\
0,9\end{array}$ & $\begin{array}{c}5,2 \pm \\
0,1\end{array}$ \\
\hline Оборудование & $\begin{array}{c}544,3 \pm \\
9,1\end{array}$ & $\begin{array}{c}425,2 \pm \\
7,6\end{array}$ & 10,44 & 0,017 & $\begin{array}{c}49,8 \pm \\
2,7\end{array}$ & $\begin{array}{c}71,4 \pm \\
3,6\end{array}$ & 4,8 & 0,001 & $\begin{array}{c}91,6 \pm \\
2,1\end{array}$ & $\begin{array}{c}85,6 \pm \\
1,1\end{array}$ & $\begin{array}{c}5,9 \pm \\
1,0\end{array}$ & $\begin{array}{c}5,2 \pm \\
0,3\end{array}$ \\
\hline Материаловедение & $\begin{array}{c}520,4 \pm \\
9,7\end{array}$ & $\begin{array}{c}429,4 \pm \\
7,2\end{array}$ & 7,98 & 0,013 & $\begin{array}{c}53,1 \pm \\
3,1\end{array}$ & $\begin{array}{c}70,6 \pm \\
2,3\end{array}$ & 4,53 & 0,0009 & $\begin{array}{c}94,0 \pm \\
1,8\end{array}$ & $\begin{array}{c}85,8 \pm \\
2,9\end{array}$ & $\begin{array}{c}5,5 \pm \\
1,2\end{array}$ & $\begin{array}{c}5,0 \pm \\
0,4\end{array}$ \\
\hline $\begin{array}{l}\text { Экономика отрасли и } \\
\text { предприятия }\end{array}$ & $\begin{array}{c}600,4 \pm \\
9,1\end{array}$ & $\begin{array}{c}512,8 \pm \\
8,6\end{array}$ & 7,31 & 0,013 & $\begin{array}{c}56,6 \pm \\
1,5\end{array}$ & $\begin{array}{c}70,5 \pm \\
1,3\end{array}$ & 5,06 & 0,0007 & $\begin{array}{c}91,3 \pm \\
2,2\end{array}$ & $\begin{array}{c}87,8 \pm \\
2,6\end{array}$ & $\begin{array}{c}6,3 \pm \\
0,9\end{array}$ & $\begin{array}{c}5,8 \pm \\
0,8\end{array}$ \\
\hline $\begin{array}{l}\text { Основы } \\
\text { художественного } \\
\text { конструирования }\end{array}$ & $\begin{array}{c}519,3 \pm \\
8,6\end{array}$ & $\begin{array}{c}459,3 \pm \\
7,7\end{array}$ & 5,64 & 0,008 & $\begin{array}{c}58,9 \pm \\
1,6\end{array}$ & $\begin{array}{c}67,1 \pm \\
1,8\end{array}$ & 3,4 & 0,0004 & $\begin{array}{c}88,5 \pm \\
1,7\end{array}$ & $\begin{array}{c}87,2 \pm \\
2,9\end{array}$ & $\begin{array}{c}5,8 \pm \\
0,8\end{array}$ & $\begin{array}{c}5,2 \pm \\
1,1\end{array}$ \\
\hline Специальный рисунок & $\begin{array}{c}587,1 \pm \\
9,5\end{array}$ & $\begin{array}{c}536,2 \pm \\
8,1\end{array}$ & 4,24 & 0,008 & $\begin{array}{c}52,1 \pm \\
1,4\end{array}$ & $\begin{array}{c}56,3 \pm \\
1,4\end{array}$ & 2,2 & 0,0002 & $\begin{array}{c}91,8 \pm \\
1,5\end{array}$ & $\begin{array}{c}90,4 \pm \\
3,1\end{array}$ & $\begin{array}{c}6,3 \pm \\
0,3\end{array}$ & $\begin{array}{c}5,9 \pm \\
0,2\end{array}$ \\
\hline $\begin{array}{l}\text { История } \\
\text { родного края }\end{array}$ & $\begin{array}{c}603,8 \pm \\
20,2\end{array}$ & $\begin{array}{c}551,6 \pm \\
8,4\end{array}$ & 2,41 & 0,008 & $\begin{array}{c}54,7 \pm \\
3,1\end{array}$ & $\begin{array}{c}59,1 \pm \\
1,6\end{array}$ & 1,26 & 0,0002 & $\begin{array}{c}91,6 \pm \\
3,2\end{array}$ & $\begin{array}{c}90,3 \pm \\
2,9\end{array}$ & $\begin{array}{c}6,5 \pm \\
0.2\end{array}$ & $\begin{array}{c}6,1 \pm \\
0,2\end{array}$ \\
\hline $\begin{array}{l}\text { Этика и культура } \\
\text { общения }\end{array}$ & $\begin{array}{c}498,7 \pm \\
16,5\end{array}$ & $\begin{array}{c}455,3 \pm \\
7,5\end{array}$ & 2,46 & 0,022 & $\begin{array}{c}56,8 \pm \\
1,9\end{array}$ & $\begin{array}{c}61,4 \pm \\
1,5\end{array}$ & 1,9 & 0,0002 & $\begin{array}{c}89,7 \pm \\
1,9\end{array}$ & $\begin{array}{c}88,1 \pm \\
2,1\end{array}$ & 5,5 & 5,1 \\
\hline $\begin{array}{l}\text { Основы безопасности } \\
\text { жизнедеятельности }\end{array}$ & $\begin{array}{c}401,6 \pm \\
6,9\end{array}$ & $\begin{array}{c}463,6 \pm \\
8,1\end{array}$ & 6,2 & 0,008 & $\begin{array}{c}55,2 \pm \\
2,4\end{array}$ & $\begin{array}{c}49,8 \pm \\
1,8\end{array}$ & 1,8 & 0,0002 & $\begin{array}{c}87,9 \pm \\
2,6\end{array}$ & $\begin{array}{l}90,2 \pm \\
3,5\end{array}$ & 4,9 & 5,1 \\
\hline Охрана труда & $\begin{array}{c}401,8 \pm \\
5,4\end{array}$ & $\begin{array}{c}445,3 \pm \\
2,1\end{array}$ & 8,17 & 0,006 & $\begin{array}{c}59,7 \pm \\
2,4\end{array}$ & $\begin{array}{c}54,3 \pm \\
1,3\end{array}$ & 1,98 & 0,0002 & $\begin{array}{c}87,0 \pm \\
2,4\end{array}$ & $\begin{array}{c}89,1 \pm \\
4,0\end{array}$ & 4,6 & 5,1 \\
\hline $\begin{array}{l}\text { Адаптивная } \\
\text { физическая культура }\end{array}$ & $\begin{array}{c}481,1 \pm \\
4,4\end{array}$ & $\begin{array}{c}571,2 \pm \\
9,1\end{array}$ & 9,14 & 0,013 & $\begin{array}{l}54,1 \pm \\
1,3\end{array}$ & $\begin{array}{c}43,4 \pm \\
5,4\end{array}$ & 1,93 & 0,0005 & $\begin{array}{c}89,8 \pm \\
2,8\end{array}$ & $\begin{array}{c}92,9 \pm \\
1,3\end{array}$ & 5,3 & 6,1 \\
\hline
\end{tabular}

Таблица 2. Результаты распределения уровней работоспособности учащихся по дням недели

\begin{tabular}{|c|c|c|c|}
\hline Дни недели & Количество просмотренных букв & Общее количество знаков в тесте & Значение $K(\%)$ \\
\hline Понедельник & $121 \pm 5,2$ & \multirow{6}{*}{868} & 14 \\
\hline Вторник & $170 \pm 1,9$ & & 19,7 \\
\hline Среда & $171 \pm 0,9$ & & 19,7 \\
\hline Четверг & $149 \pm 2,5$ & & 17,2 \\
\hline Пятница & $133 \pm 1,3$ & & 15,4 \\
\hline Суббота & $120 \pm 6,2$ & & 14 \\
\hline
\end{tabular}


(СанПиН 1186-03) и выявили схожесть полученных данных с распределением, приведенным в санитарных правилах. Таким образом, полученную шкалу утомительности считали возможным приравнивать к шкале трудности и именовать аналогично.

Гигиеническая оценка расписания показала, что в группе подростков, осваивающих профессию оператора швейного оборудования, выявлено неравномерное распределение учебной нагрузки в течение недели: она постепенно нарастала с понедельника по среду, неравномерно снижалась с четверга по субботу с подъемом в пятницу.

Оценка расписания группы, осваивающей профессию обувщика по ремонту обуви, также показала неравномерное распределение учебной нагрузки в течение недели. Максимальная учебная нагрузка приходилась на понедельник и пятницу, постепенного ее нарастания и снижения не отмечалось. Учебное расписание в обеих группах оценено как нерациональное, что явилось основанием для разработки мероприятия по коррекции и оптимизации

\section{Применение программы автоматизированного составления расписания}

Поскольку составление учебного расписания трудоемкий процесс, оно стало объектом автоматизации. Была разработана и зарегистрирована компьютерная программа автоматизированного составления расписания («Программа автоматизированного составления расписания в учреждении начального профессионального образования» (свидетельство 2016612429, дата государственной регистрации 26 февраля 2016 г.). Ядро системы и интерфейсная часть были написаны на языке CSharp 2010, вид и версия операционной системы — MicrosoftVisual Studio.
Разработанная нами программа основана на распределении учебных дисциплин по дням недели в соответствии с их степенью сложности, выраженной в баллах. Программа направлена на составление учебного расписания в соответствии с кривой недельной работоспособности и коэффициентом ежедневной учебной нагрузки учащихся с ОВ.

Начальным этапом работы с программой являлось введение входных данных: название учреждения, наименование специальности, курс, группа. Название учреждения и наименование специальности имели текстовый формат, курс и группа - числовой.

Следующим этапом было введение количества учебных часов по каждому предмету за неделю в числовом формате. Изучаемые предметы введены в программный код в соответствии с базовым учебным планом.

Финальным этапом работы программы являлось автоматизированное составление расписания для групп учащихся в соответствии с заданными критериями сложности учебных дисциплин.

Использование программы автоматизированного составления расписания позволило составить учебное расписание, соответствующее основным гигиеническим требованиям и принципам биоритмологии.

После 6 месяцев обучения подростков по составленному расписанию выявлены изменения в показателях УР: число подростков, имеющих средние значения уровней работоспособности до начала занятий, увеличилось на 21,3\% (p < 0,05) и составило 21,6 $\pm 3,2 \%$. Число подростков с низким уровнем работоспособности сократилось на 7,7\% (p > 0,05) и составило 59,2\%; с уровнем работоспособности выше среднего увеличилось на 45,7\% ( $>$ < 0,05) и составило 5,1\% от общего числа обучающихся.

Показатели УР по окончании занятий также перераспределялись в сторону увеличения количества

Таблица 3. Критерии бальной оценки учебных предметов в соответствии с динамикой показателей ЦНС учащихся

\begin{tabular}{|l|c|c|}
\hline \multicolumn{1}{|c|}{ Критерии оценки } & Изменение количества просмотренных знаков & Изменение количества ошибок \\
\hline Крайне низкие значения (менее $M-2 \sigma)$ & $-27,0-18,1 \%$ & $+27,0+18,1 \%$ \\
\hline Низкие значения $(M-2 \sigma)$ & $-18,0-9,1 \%$ & $+18,0+9,1 \%$ \\
\hline Ниже среднего $(M-1 \sigma)$ & $-9,0-0 \%$ & $+9,0+0 \%$ \\
\hline Средние значения $(M \pm 1 \sigma)$ & $+0+9,0 \%$ & $-0-9,1 \%$ \\
\hline Значения выше среднего $(M+2 \sigma)$ & $+9,1+18,0 \%$ & $-9,0-18,1 \%$ \\
\hline Высокие значения (более $M+2 \sigma)$ & $+18,1+27,0 \%$ & $-18,0-27,0 \%$ \\
\hline
\end{tabular}

Таблица 4. Ранговая шкала утомительности учебных предметов

\begin{tabular}{|l|l|l|}
\hline \multicolumn{2}{|c|}{ Предмет } & \multicolumn{2}{|c|}{ Ранг трудности (балл) } \\
\hline \multicolumn{2}{|c|}{ Првоении профессии «обувщик по ремонту обуви» } \\
\hline «технология обуви», «оборудование», «материаловедение обувного производства» & 6 \\
\hline «экономика отрасли и предприятия», «основы художественного проектирования и конструирования обуви» & 5 \\
\hline «производственное обучение» & 3 \\
\hline «охрана труда» & 2 \\
\hline «физическая культура» освоении профессии «оператор швейного оборудования» & 1 \\
\hline & 6 \\
\hline «технология изготовления швейных изделий», «оборудование», «материаловедение» & \\
\hline «основы конструирования» & 5 \\
\hline «специальный рисунок», «история родного края», «этика и культура общения» & \\
\hline «производственное обучение» & 4 \\
\hline «охрана труда», «основы безопасности жизнедеятельности» & 3 \\
\hline «физическая культура» & 2 \\
\hline
\end{tabular}


учащихся со средним уровнем работоспособности (на $40 \% ; p<0,05)$ и уровнем работоспособности выше среднего (на 3,1\%; $p>0,05$ ). Одновременно сократилось число учащихся с низким уровнем работоспособности (на 9,1\%; $p \leq 0,05)$.

Результаты повторного анализа психосоматических жалоб учащихся показали сокращение доли жалоб неспецифического характера на 52\%, жалоб на работу сердечно-сосудистой системы и органов дыхания на 46,6\%. Однако значения интенсивности жалоб на деятельность опорно-двигательного аппарата оставались прежними, поскольку изменение учебного расписания не сопровождалось изменением алгоритма профессионального обучения.

Анализ уровней ситуативной тревожности показал смещение данного показателя в сторону умеренных уровней. Уровень личностной тревожности достоверно не изменялся, что отражало особенности личностного темперамента учащихся.

Автоматизация в составлении расписания позволила повысить оперативность и четкость за счет информационной поддержки, кроме того, позволила оптимизировать ограниченные трудовые ресурсы преподавательского состава.

\section{ОБСУЖДЕНИЕ РЕЗУЛЬТАТОВ}

Изучение условий профессионального обучения подростков С ОВ позволило выявить нарушения санитарно-гигиенических требований на отдельных рабочих местах. Так, к вредным физическим факторам производственной среды при освоении учащимися рабочих профессий относились: недостаточный уровень искусственной освещенности, превышение уровня звукового давления; к вредным химическим факторам загрязнения воздуха рабочей зоны: уровень пыли, содержание органических растворителей и аллергенов. Таким образом, условия профессионального обучения подростков считали вредными, а труд - тяжелым в соответствии с классификацией условий труда. Это совпадает с результатами, полученными другими авторами, показавшими несоответствие условий обучения гигиеническим нормативам [19]. Более того, вредные факторы производственной среды и трудового процесса (1-3-й степени) сохраняются и при дальнейшем трудоустройстве таких лиц, способствуя формированию профессионально обусловленной патологии [20].

В результате комплексной оценки образовательного процесса в интернате для обучения лиц с ОВ установлено, что профессиональные занятия по продолжительности различных видов деятельности и частоте их чередования не соответствуют рациональному учебному расписанию. В итоге у подростков обеих специальностей было выявлено: снижение умственной работоспособности, низкие уровни ситуативной тревожности (у 76,2\%), неудовлетворительный уровень биологической адаптации (у 44,85\%), напряжение механизмов адаптации (у 21,2\%). Общая заболеваемость учащихся, по данным обращаемости во втором полугодии обучения, достоверно превышала показатели первого полугодия, соответственно 7,08 и 5,23 на 1000 человек $(p<0,01)$.

В ходе исследования с учетом данных функциональных особенностей деятельности организма подростков с ОВ была разработана и внедрена компьютерная программа автоматизированного составления расписания. Эффективность программы по гигиенически рациональному расписанию, составленная на основе шкалы трудностей учебных дисциплин, была подтверждена спустя 6 месяцев обучения подростков. Результаты ее внедрения позволили на 52\% сократить доли жалоб подростков на самочувствие неспецифического характера, на 46,6\% уменьшить жалобы на работу сердечно-сосудистой и дыхательной систем. Вместе с этим, уровни ситуационной тревожности подростков смещались в сторону умеренных значений, увеличивалось количество учащихся со средними значениями умственной работоспособности.

Для сокращения неблагоприятного воздействия факторов учебно-производственной среды на организм подростков руководству интерната были подготовлены методические рекомендации, согласованные с Роспотребнадзором по Саратовской области и включающие необходимость проведения конкретных мероприятий:

- выделение помещений для организации занятий профессионального цикла, соответствующих по площади и объему наполняемости групп, или сокращение числа обучающихся в группах;

- установку вытяжного шкафа в мастерской для освоения профессии обувщик по ремонту обуви для выполнения клеевых рабочих операций;

- внедрение фризкультурных пауз в связи с необходимостью выполнения учащимися рабочих операций в вынужденной рабочей позе в положении сидя более 80\% времени практического занятия;

- установку местных источников освещения на верстаках в мастерских обувщиков и на рабочих местах для выполнения ручных и машинных рабочих операций при освоении профессии оператора швейного оборудования;

- использование средств индивидуальной защиты при выполнении рабочих операций для защиты организма от неблагоприятного воздействия шума: пробки, шлем, заглушки, наушники; от воздействия вибрации: рукавицы с вкладышами, рукавицы и перчатки с наладонниками, прокладки и пластины для обхвата вибрирующих рукояток и деталей;

- контроль эффективности работы системы вентиляции, ее своевременное технические и санитарное обслуживание в помещениях, оборудованных для освоения профессий;

- повышение мотивации учащихся к ведению здорового образа жизни.

\section{ВЫВОДы}

Профессиональное обучение подростков с ОВ здоровья осуществляется в неблагоприятных санитарногигиенических условиях. При оценке условий обучения в процессе освоения профессии обувщика по ремонту обуви выявлено химическое загрязнение воздуха мастерских (ацетон - 4,5 ПДК, оксид углерода $-1,5$ ПДК), профессии оператора швейного оборудования фактор напряженности трудового процесса (наблюдение за 1 объектом более 40\% времени занятия), превышение ПДУ шума на рабочих местах в 1,6 раза. Определено нерационально составленное расписание учебных занятий, что также может являться фактором риска нарушения адаптационных процессов при реализации прав учащихся с ОВ на обучение и доступный труд. Это подтверждает необходимость оптимизации условий очного профессионального обучения данного контингента в системе учреждений среднего профессионального образования. По результатам 
исследования разработана и внедрена эффективная компьютерная программа автоматизированного составления расписания, позволяющая улучшить психосоматическое состояние здоровья и вдвое снизить количество жалоб на самочувствие, а следовательно, обеспечить соответствие условий обучения и требований профессий функциональным возможностям лиц С нарушениями здоровья.

\section{Литература}

1. Шубочкина Е. И., Молчанова С. С., Ибрагимова Е. М., Куликова А. В. Гигиенические и медико-социальные проблемы подготовки учащихся в профессиональных колледжах. Гигиена и санитария. 2009; 2: 6-29.

2. Истомин А. В., Кирюшин В. А., Елисеев Ю. Ю., Клещина Ю. В. Тяптиргирянова В. М. Обзор научно-практических конференций, посвященных современным проблемам гигиены, просилактики и охраны здоровья населения за 2012 год. Здоровье населения и среда обитания. 2013; (3): 38-3.

3. Мочалова Е. К. Качество жизни подростков-инвалидов важная проблема современности. Вопросы современной педиатрии. 2006; (5): 396-398.

4. Алаева Н. С. Разработка технологий дистанционного обучения инвалидов с депривацией слуха. Открытое и дистанционное образование. 2008; (3): 21-28.

5. Беляевский Б. В. Проблемы трудового обучения и профессиональной подготовки детей и подростков с недостатками интеллектуального развития. Специальное образование. 2009; (4): 5-19.

6. Берсенев М. В., Мусабиров И. Л. Центр сопровождения студентов с инвалидностью как проектный офис: основные практики и рекомендации. Вестник Томского государственного университета. 2011; (3): 188-91.

7. Кучма В. Р. Формирование здорового образа жизни детей и единого просилактического пространства в образовательных организациях: проблемы и пути решения. Гигиена и санитария. 2015; 94 (6): 20-5.

8. Ибрагимова Е. М. Гигиеническая оценка разных форм подготовки подростков рабочим профессиям в профессиональных колледжах [диссертация]. М., 2009.

9. Казаева О. В. Гигиенические и медико-социальные аспекты профессионального обучения подростков (на примере образовательных учреждений начального профессионального образования машиностроительного профиля) [диссертация]. Рязань, 2011.

\section{References}

1. Shubochkina El, Molchanova SS, Ibragimova EM, Kulikova AV. Gigienicheskie i mediko-social'nye problemy podgotovki uchashhihsja v professional'nyh kolledzhah. Gigiena i sanitarija. 2009; 2: 6-29.

2. Istomin AV, Kirjushin VA, Eliseev YuYu, Kleshhina JuV, Tjaptirgirjanova VM. Obzor nauchno-prakticheskih konferencij, posvjashhennyh sovremennym problemam gigieny, profilaktiki ohrany zdorov'ja naselenija za 2012 god. Zdorov'e naselenija i sreda obitanija. 2013; (3): 38-3.

3. Mochalova EK. Kachestvo zhizni podrostkov-invalidov — vazhnaja problema sovremennosti. Voprosy sovremennoj pediatrii. 2006; (5): 396-398

4. Alaeva NS. Razrabotka tehnologij distancionnogo obuchenija invalidov s deprivaciej sluha. Otkrytoe i distancionnoe obrazovanie. 2008; (3): 21-8.

5. Beljaevskij BV. Problemy trudovogo obuchenija i professional'noj podgotovki detej i podrostkov s nedostatkami intellektual'nogo razvitija. Special'noe obrazovanie. 2009; (4): 5-19.

6. Bersenev MV, Musabirov IL. Centr soprovozhdenija studentov s invalidnost'ju kak proektnyj ofis: osnovnye praktiki i rekomendacii.

10. Елисеева Ю. В., Дубровина Е. А., Елисеев Ю. Ю., Истомин А. В. Состояние реализации здоровьесберегающих технологий в образовательных учреждениях. Здоровье населения и среда обитания. 2017; 4 (289): 35-7.

11. Гончарова Г. А., Надеждин Д. С. Формирование социальнопсихологической адаптации школьников и учащихся профессиональных училищ. Гигиена и санитария. 2009; (2): 30-3.

12. Кожевникова Н. Г. Особенности заболеваемости студентовподростков в процессе адаптации к обучению в вузе Педиатрия. Журнал им. Г. Н. Сперанского. 2012; 91 (5): 142-5.

13. Смирнов Н. К. Здоровьесберегающие образовательные технологии в современной школе. М., 2002; 121 с.

14. Нефедов П. В., Кутумова Н. Б. Способ формирования ежедневной учебной нагрузки детей-инвалидов с нарушением слуха младших и старших классов. Патент РФ № 2006143491/14. 20.06.2008.

15. Абабков В. А., Бизюк А. П., Володин Н. Н. Клиническая психология. М., 2004; 956 с.

16. Ратанова Т. А., Шляхта Н. Ф. Психодиагностические методики изучения личности. М., 2003; 234 с

17. Баевский Р. М., Лаубе В., Берсенева А. П. Исследование механизмов вегетативной регуляции кровообращения на основе ортостатического тестирования с использованием математического анализа ритма сердца. Вестник Удмуртского университета. Серия Экономика и право. 1995; (3): 3.

18. Куинджи Н. Н. Валеология: пути формирования здоровья школьников. М., 2001; 136 с.

19. Бубнова Е. В., Гусева Н. К. Социальные аспекты реабилитации инвалидов, получающих начальное профессиональное образование на базе Нижегородского училища-интерната для инвалидов. Медико-социальная экспертиза и реабилитация. 2008; (1); 12-4.

20. Гиндюк А. В. Обоснование гигиенических требований к условиям труда инвалидов по слуху [диссертация]. Минск, 2015.

Vestnik Tomskogo gosudarstvennogo universiteta. 2011; (3): 188-91.

7. Kuchma VR. Formirovanie zdorovogo obraza zhizni detej i edinogo profilakticheskogo prostranstva $\vee$ obrazovatel'nyh organizacijah: problemy i puti reshenija. Gigiena i sanitarija. 2015; 94 (6): 20-5.

8. Ibragimova EM. Gigienicheskaja ocenka raznyh form podgotovki podrostkov rabochim professijam v professional'nyh kolledzhah [dissertacija]. M., 2009.

9. Kazaeva OV. Gigienicheskie i mediko-social'nye aspekty professional'nogo obuchenija podrostkov (na primere obrazovatel'nyh uchrezhdenij nachal'nogo professional'nogo obrazovanija mashinostroitel'nogo profilja) [dissertacija]. Rjazan', 2011.

10. Eliseeva YuV, Dubrovina EA, Eliseev YuYu, Istomin AV. Sostojanie realizacii zdorov'esberegajushhih tehnologij $\vee$ obrazovatel'nyh uchrezhdenijah. Zdorov'e naselenija i sreda obitanija. 2017; 4 (289): 35-7.

11. Goncharova GA, Nadezhdin DS. Formirovanie social'nopsihologicheskoj adaptacii shkol'nikov i uchashhihsja professional'nyh uchilishh. Gigiena i sanitarija. 2009; (2): 30-3.

12. Kozhevnikova NG. Osobennosti zabolevaemosti studentov- 


\section{ORIGINAL RESEARCH I HYGIENE AND PREVENTION}

podrostkov $v$ processe adaptacii k obucheniju v vuze. Pediatrija. Zhurnal im. GN Speranskogo. 2012; 91 (5): 142-5.

13. Smirnov NK. Zdorov'esberegajushhie obrazovatel'nye tehnologii v sovremennoj shkole. M.: 2002; $121 \mathrm{~s}$.

14. Nefedov PV, Kutumova NB. Sposob formirovanija ezhednevnoj uchebnoj nagruzki detej-invalidov s narusheniem sluha mladshih i starshih klassov. Patent RF \# 2006143491/14. 20.06.2008.

15. Ababkov VA, Bizjuk AP, Volodin NN. Klinicheskaja psihologija. M., 2004; $956 \mathrm{~s}$.

16. Ratanova TA, Shljahta NF. Psihodiagnosticheskie metodiki izuchenija lichnosti. M., 2003; 234 s.

17. Baevskij RM, Laube V, Berseneva AP. Issledovanie mehanizmov vegetativnoj reguljacii krovoobrashhenija na osnove ortostaticheskogo testirovanija $s$ ispol'zovaniem matematicheskogo analiza ritma serdca. Vestnik Udmurtskogo universiteta. Serija Jekonomika i pravo. 1995; (3): 3.

18. Kuindzhi NN. Valeologija: puti formirovanija zdorov'ja shkol'nikov. M., 2001; 136 s.

19. Bubnova EV, Guseva NK. Social'nye aspekty reabilitacii invalidov, poluchajushhih nachal'noe professional'noe obrazovanie na baze Nizhegorodskogo uchilishha-internata dlja invalidov. Medikosocial'naja jekspertiza i reabilitacija. 2008; (1), 12-4.

20. Gindjuk AV. Obosnovanie gigienicheskih trebovanij $k$ uslovijam truda invalidov po sluhu [dissertacija]. Minsk, 2015. 